\title{
Innovation in the occupational health physician profession requires the development of a work collective to improve the efficiency of MSD prevention
}

\author{
S. Caroly ${ }^{\mathrm{a}}$, A. Landry ${ }^{\mathrm{a}}$, C. Cholez ${ }^{\mathrm{a}}$, P. Davezies ${ }^{\mathrm{b}}, \mathrm{M}$. Bellemare $^{\mathrm{c}}$ and N. Poussin ${ }^{\mathrm{d} \mathbf{1}}$ \\ ${ }^{a}$ Laboratory PACTE, University of Grenoble, Sandrine.Caroly@upmf-grenoble.fr, Le Patio, BP 47,38040 \\ Grenoble Cedex 09, France \\ ${ }^{\mathrm{b}}$ University of Lyon, France \\ ${ }^{c}$ Department of industrial relations, University Laval, Québec, Canada \\ ${ }^{d}$ Laboratory clinical activity, CNAM, 41 rue Gay Lussac, 75005 Paris, France
}

\begin{abstract}
Given the ageing population of occupational health physicians and the deteriorating situation of employee health, reforms targeting the multi-disciplinary nature of occupational health are currently being drawn up. These are of great concern to doctors in terms of the future of occupational health, notably with regard to changing medical practices. The objective of this study is to explore the actual practices of occupational health physicians within the framework of MSD prevention in France. By analysing the activity of occupational health physicians, we could gain a better understanding of the coordination between those involved in OHS with the ultimate goal being to improve prevention. Based on an analysis of peer activity, this method made it possible to push beyond pre-constructed discourse. According to activity theories, it is through others that the history and controversies of a profession can be grasped and skills developed. The results produced by these collective discussions on activity analysis contributed to establish a collective point of view about the important aspects of their profession that need defending and the variations in professional genre in relation to the current reforms, notably.
\end{abstract}

Keywords: occupational health physician, activity; professional genre, innovation

\footnotetext{
${ }^{1}$ With the collaboration of F. Coutarel, K. Chassaing, J. Petit, A. Garrigou, G. Fernandez, G. Baril-Gingras, D. Prudhommes, F. Daniellou, researchers who also took part in this action-research on occupational health physicians as part of the ANR SEST 2009
} 


\section{Introduction}

The number of cases of MSD has been steadily increasing for several years and is today a priority for occupational health and prevention at international level. In France, in 2008, 36,926 cases of MSD were covered by the national health structure. The number of new cases of MSD covered by national health has been growing by $13 \%$ a year since 1995 . MSD represents the primary cause of occupational illness in Europe and France (source: Eurostat) engendering substantial human and socio-economic costs ${ }^{2}$.

To counter this plague, the production of knowledge in biomechanics, physiology, epidemiology, ergonomics and, more recently, in work psychology, has striven to improve the etiology of this phenomenon (notably the link between physical and psychological aspects). Research on prevention possibilities has been mainly geared towards secondary and tertiary prevention (improvements to tools and workstations to keep people at work and training in the correct body movements). However, improvements to primary prevention have been insufficient, even though workstation and work organisation-related risk factors have been clearly identified $[1,2]$.

As revealed by the latest international scientific discussions (PREMUS 2010 congress, $3^{\text {rd }}$ Frenchspeaking congress), today research needs to produce knowledge about the action produced through ergonomic intervention work $[3,4,5]$ and assessment of its effectiveness for prevention [6]. It appears necessary to better understand the conditions for implementing ergonomic action and the room for manoeuvre available for setting up effective, lasting prevention [7]. Indeed, successful ergonomic intervention in the occupational health field depends greatly on the conditions in which this intervention is set up and the eagerness of professionals [8] to become involved in a prevention project according to company context and institutional occupational health and safety systems.

Our research on the lasting prevention of MSD [7] pointed to the role of the occupational health physician as one of the professionals able to make ergonomic intervention work more effective. When the aim is to set up lasting prevention in a company, the occupational health physician would appear to be a determining stakeholder in that he or she is able to

\footnotetext{
2 In France in 2008, 8.4 million working days lost and 787 million euros in expenses covered through company national insurance contributions.
}

paint a precise picture of worker health and acts as a whistleblower with respect to the employer and the company occupation health, safety and working conditions committee [9]. Yet, out of the 30 company cases studied, the occupational health physician practices observed proved to be highly diverse: distant positions, conflict situations, investments in partnerships, etc. There are several reasons for this heterogeneity in practices: a lack of training in MSD risk diagnosis, employee monitoring that is not always possible, insufficient participation in company design or change projects, etc. Indeed, it is more a question of occupational health physicians lacking the means of involving the medical field in companies, rather than their inability to do their job, which is how many internal or external company stakeholders perceive the situation.

As part of new research on occupational health physician MSD prevention practices, financed by the French National Research Agency (ANR), we have tried to better understand the activity of this key professional. The aim is to study how effective and lasting MSD prevention might be set up by exploring potential room for manoeuvre.

\section{The context of occupational health in France}

Within the framework of occupational health and prevention in France, occupational health physicians play an essential role: they collect occupational health data from the complaints expressed by employees during their medical check-up or filed on nurses' registers, they provide information on occupational health statements, they deliver certificates of fitness with restrictions, they provide advice when employees return to work, they follow up employees returning to work, they help to adapt jobs or workstations, etc. In France, occupational health physicians have two types of activity. One is medical and involves them seeing employees in their surgery - recruitment medical visits, yearly or twoyearly check-ups and consultation following a long period of sick leave - and the other concerns incompany actions. The latter activity accounts for $1 / 3$ of their time (they attend company occupational health, safety and working conditions committee meetings, help with the design of workstations, provide information and raise awareness about professional risks, etc.).

While their framework of action is defined by their missions, occupational health physicians are not 
always able to act in all situations. For example, company managers are sometimes helpless faced with the MSD phenomenon and the difficulty of introducing improvements. As for employees, they are sometimes afraid to lose their job and therefore hide their pain from the physician. Then there are external partners in charge of performing maintenance and adaptation work on equipment. As their workload is often too high, the delays caused lead to the desocialisation of employees on sick leave. As well as the difficulty finding solutions to such problems, occupational health physicians are alone as they strive to fulfil the contradicting requirements of their activity (for example, signing a cleaning lady's certificate of fitness when the employee clearly suffers from MSD but is afraid to lose her job). Faced with situations where there are conflicting goals or conflicts between ends and means, occupational health physicians are forced to question their choices and decisions with respect to a company or an employee on a daily basis. Often prevented from performing their activity, occupational health physicians experience mental suffering similar to that of general practitioners [10]. Their situation is all the more difficult given that they have very few opportunities to discuss the dilemmas of their activity with their peers. Indeed, whether they are employed by an inter-company occupational health department or work in a company with a prevention service, these health physicians very rarely meet up with each other except within the framework of a few specific projects. The solitary nature of the occupational medicine profession is wearing on the health physicians exercising it [11].

In spite of this, occupational medicine is a constant topic of discussion within the professional community and is subject to controversy when big meetings are organised, such as the national occupational health conference or professional discussion meetings supported by various associations (SMT, Cisme, etc). Many of the sociopolitical debates about occupational health approaches revolve around occupational medicine [12]: specialist medicine, prevention or occupational health medicine, changes to risk prevention approaches to make them more effective, etc. Thus, understanding occupational health physicians' scope of action in the prevention of MSD is an important challenge for occupational health ergonomists. The job of occupational health physician is constantly changing in terms of professional practices owing to technical and organisational transformations in companies (ongoing change, introduction of new technologies, etc.) and changes to working populations (ageing, increasing unfitness, job feminisation, etc.).

In response to physicians' difficulties acting on prevention, several reforms have been introduced one after the other, notably focusing on greater interdisciplinarity as a means of managing the limits of the French prevention system $[13,14]$. The future of occupational medicine in France has been further undermined by the fact that demographic changes to the profession will prevent it from being practiced in the same way in the future. New jobs have also appeared in the prevention field (occupational risk prevention officers) and complex risk prevention problems such as MSD or psychosocial risks require a multi-disciplinary approach drawing on various skills. These changes call into question the action of prevention officers and their role in prevention and that of occupational health physicians according to different forms of logic [15]: whistle-blowing logic, management logic and prevention logic.

Coordination between the different stakeholders is still far from reflecting a multidisciplinary approach based on each professional's skills and creating new forms of prevention action. Integrating occupational health and prevention logic into corporate in-house logic, such as profitability, production, continuous improvement and quality, is still a difficult accomplishment [16]. Given the diversity of stakeholders, it is not surprising that the conditions for involving occupational health physicians are difficult. It is not going to be easy for occupational health physicians to collaborate with the other professionals. This collaboration will have to be built up over time. It will require adjustments in the coordination between health and safety professionals and their corporate intervention work but also in occupational health physicians' participation in company change projects and their relations with decision-makers, management and designers. This is why it is important to clearly identify the activity of occupational health physicians in order to implement effective cooperation for improved MSD prevention.

\section{Objectives and theoretical framework}

The objective of this research is to show that innovation in a profession requires the development of a work collective. It involves participating in the development of health physicians' skills to help them adapt their job to their activity. By building 
collectives of peers, physicians will be able to recognise what they do in the activity of others and this will help them to create room for manoeuvre in their efforts to prevent MSD. Faced with the challenge of creating new resources, we shall show that collective discussions about the traces of their activity will lead the health physicians to develop a collective point of view, and hence contribute to innovation in their field and the construction of their own health.

Three theoretical frameworks are used here in relation to the definition of this objective: (1) social innovation, (2) activity theories and, finally, (3) the notion of work collective.

(1) Traditionally, innovation in ergonomics is addressed through the field of work system design. It refers to a creative activity: instrumental genesis [17], inventiveness process [18], dialogism and mutual learning [19], and anticipation of the future [20]. In the design field, innovation is often the result of cooperation between designers in relation to users [21]. The meeting between worlds in the design activity is a challenge for innovation [22].

But innovation is also rarely addressed outside of technical or production aspects, notably from the point of view of society and the social and professional developments of jobs and employment. In this article, innovation approaches in ergonomics will be reviewed through the notion of social innovation in order to better understand the role of collectives in the innovation process of a profession.

Situated outside of market concerns and based on the notion of sharing, social innovation consists in developing new responses to partially satisfied or unfulfilled social or environmental needs by encouraging all the stakeholders involved (public, private and civil) to cooperate. The notion of innovative society refers to the ability of societies to see themselves as targets of innovation, beyond the organisations traditionally dedicated to innovation such as public and private R\&D organisations. Social innovation is initiated by stakeholders to respond to an aspiration, meet a need, provide a solution or benefit from an opportunity for action in order to modify social relations, transform an action framework or put forward new cultural ideas. In this definition, innovation is the fruit of collective work ${ }^{3}$ and creates well-being in the stakeholders. In ergonomics, innovation in work is linked to enabling environments, such as the development of new skills

\footnotetext{
3 Innovation is not a linear process but a process whereby diversified stakeholders confront each other (Callon, 1986)
}

and knowledge or the extension of means to take action.

(2) Activity ergonomics is being developed on the international scene and is part of many discussions with other disciplines interested in the concept of activity. According to Wisner [19], activity is built by a given operator as a response to a given context. In this sense, activity is performed in specific contexts that vary according to their material, organisational and social dimensions and involve the operator using their body and mind to strive towards the dual objective of effectiveness and health.

In the Activity Theory movement, based on thinking supported by the historico-cultural school, notably promoted by Vygotski and Léontiev, activity is the product of the history of a subject and its social surroundings. From this viewpoint, activity is not only the result of an action but "the widening of the field of action is a typical and fundamental characteristic of human development" [18]. Activity encompasses something broader than action and operations.

In other words, individual activity is constructed within social activity and, in exchange, social activity enables individual activity to develop. There is no subject activity that does not concern the appropriation of socially constructed worlds and knowledge and that does not refer to people's subjectivity. The subject's ability to act [22] depends on this psychological and social function, in other words on the possibilities to "recreate the outside from the inside" in the subject's activity.

A subject's power to act stemming from a work collective raises new questions about the conditions for creating room for manoeuvre.

(3) Collective activity, in the strict sense of the term, is defined as the performance of a task leading to actions coordinated by several operators: collective activity is not a medley of individual activities but the joint performance of the same task by several operators, in places and times that may be common or different. This definition only explains part of collective activity, i.e. that of the work collective whose forms may vary (co-action, cooperation, collaboration or mutual aid between operators as work is performed). Indeed, collective activity is broader than a work collective. It includes the work collective inside which the operator is integrated and acts [23].

In the case of occupational health physicians, activity is above all individual and the work collective can have varying degrees of development. The occupational health physician may belong to a 
team in an occupational health department comprising other health physicians or other multidisciplinary professionals. This does not mean that any collective work is performed or that a work collective actually exists.

The notion of work collective is relatively recent and polysemous. A work collective exists when several workers strive to complete a common work according to their own action rules and professional rules. The work collective is set up inside and by this rule-producing activity, which corresponds to a set of goals other than those defined by the task. The work collective requires that the different professions solve their own internal conflicts by building genres before they can be attuned to each other.

From this point of view, the work collective may be present in the individual activity of an occupational health physician in the way the physician regulates internal and external disturbances to the work situation. When integrated into individual activity, the work collective is a resource for physicians as they perform their daily prevention action. It enables them to find a way out of the dilemmas encountered in their activity and provides them with a means of getting around prevented activity. From the perspective of action, the articulation between individual activities and collective activities aims to maintain production and health objectives. In other words, collective activity makes it possible to regulate the efficiency of occupational health physicians through processes of experience pooling and sharing.

\section{Methods}

Our research is based on the objective to develop the activity of occupational health physicians. To do this, we set up two groups of volunteer occupational health physicians from different occupational health departments in a region of France.

The groups were composed as follows: one was a "mixed" group comprising 8 physicians $(2$ men and 6 women, 2 of whom were under the age of 55 and 6 were over 55), from several departments belonging to the same inter-company group, while the other was made up of 6 women physicians (2 of whom were under the age of 55 and 4 of whom were older than 55 ) belonging to the same inter-company department.

Based on peer activity analysis, the method enabled us to go beyond preconstructed discourse, which tends to undermine discussions about operating modes, prevented actions linked to contexts and relations with the employees and employer, and experience strategies. Indeed, acording to activity theories, it is in others that the history and controversies of a profession can be grasped and skills developed.

With the objective of confronting the physicians with the traces of their activity, each physician was observed individually during their medical interviews with employees or during in-company actions for a minimum of one working day and a maximum of seven working days according to a protocol defined by the national physicians' association and national data protection commission. In all, the physicians' consultation activity was observed for over 200 hours and the other one-third of their activity for roughly 100 hours.

After being shown to the physician observed during a simple self-confrontation interview, the observation trace material collected was used in discussions with the two volunteer physicians' collectives. Overall, 17 discussion sessions were held with the physicians. These focused on the practices observed: consultation, occupational health, safety and working conditions (OHS) committee, workstation/job design, and keeping employees in their jobs. These collective discussions about how they performed their activity provided each physician with openings in terms of what they could do in their MSD prevention activity.

The methods used to trigger peer discussions based on the traces of the physicians' activity were the cross self-confrontation and allo-confrontation methods. The first consists in developing a professional dialogue within the collective [22]: the idea is to ask a fellow colleague taking part in the method to comment on the activity of somebody else, who is also confronted with his or her own activity sequences. The second method consists in getting a group of participants to talk about the activity of one or several colleagues [24]. Using the observations made, both confrontation methods encouraged the collective to discuss their rules for action and for the profession as a whole.

\section{Results of the collective discussions about skills development}

The discussions produced by these peer collectives led to several results in terms of developing the physicians' MSD prevention skills. We shall focus 
here on four results: $1 /$ formalisation of experience, $2 /$ creation of new resources, $3 /$ existence of a space for managing emotions, 4 / construction of a place of debate for the re-definition of rules.

(1) The discussions between the physicians according to their age and experience and according to their work context fostered their awareness of each others' practices, notably the importance of what the physicians say and write in their relationship with the employer, the way they listen to the employee and communicate with him or her, the way they use the legislative context, etc.

(2) The discussions made it possible not only to underline the experience of each physician but also helped to pass on this experience. By integrating the words of others in their own thinking, the occupational health physicians were able to increase their room for manoeuvre. In other words, by getting to know the practices of others, they were able to create new resources and open up to other ways of acting in their work situation: creating more opportunities for contact with the OHS committee, talking about handicapping situations with employees to change their representation of a disabled worker, changing the way they examine MSD by making it less systematic and based more on the information collected during their consultation with the employee, switching from a general medicine model (with a systematic medical exam) to an occupational health physician model (more time allotted in the interview with the employee to their work organisation and relations with colleagues, for example), or reorganising the consultation procedure (starting the discussion about work and then moving on to health problems).

(3) Although these collective discussions created openings for new possibilities in the physicians' activity, they also acted as a space for managing emotions and providing the physicians with reassurance. The physicians were able to come out of their isolation and talk with the others about their suffering in difficult work situations (rejection or manipulation of the employer making the physician feel uncomfortable in their relationship with other people in the company, including the employees, paradoxical situations and the impossibility of acting). The discussions encouraged them to share the dilemmas of their profession and realise that occupational health physicians do not always have the solution. They called into question some physicians' defence and self-protection strategies, such as not going to meetings with the OHS committee or avoiding any contact with the company.

(4) The discussions produced by the physicians' collectives focused mainly on the way to redefine rules as a means of achieving effective MSD prevention. This redefining of rules appears to be a means of increasing occupational health physicians' room for manoeuvre in their daily activity. Given that these rules are the result of collective discussions and are shared by all, the room for manoeuvre afforded is all the greater.

Let us now take an example to show how the debates about activity within work collectives encourage the physicians to develop skills.

The observation extract below is from an OHS committee meeting in a supermarket, attended by a women physician of over 55 years of age. When the subject of occupational accidents and their causes is brought up at the start of the meeting by the safety officer, the occupational health physician does not contribute her analysis of the organisational factors likely to result in various accidents, including lumbago. The atmosphere in this meeting is tense and the physician speaks little. She answers the questions that the members ask her and attempts several times to bring up the question of work in the discussion but nobody really listens to her. At the end of the meeting, a conflict erupts between the physician and the committee members concerning one employee whom the physician has pronounced unfit. This was not an item on the agenda. More specifically, the occupational health physician does not satisfy the committee members' request for help invoking the requirements of medical secrecy and arguing that she cannot talk about the employee in the public space formed by the OHS committee.

The discussions between the occupational health physician and the committee members were read out entirely to the collective according to the order of exchanges and the timing of the meeting. For example:

Manager: Can you back us up with proposals?

Occupational health physician: I am not familiar with your workstations, so I'm not the best person to back you up.

Manager: I don't agree. We've adopted an approach to relocate employees, but the different people involved (including the occupational health physician) need to study the possibilities. Underlying that, there's the joint committee that decides on disability and then informs us if we've looked into all the possibilities. What type of job she 
can do. What modifications. We need to have some ideas to go on, we're not qualified to do that yet.

Occupational health physician: We have training with a legal expert. It's our job to suggest ideas, that's my responsibility. It's up to the employer to say whether there are any jobs without exposure and or whether the job can be adapted. It's not up to me to say which job.

When the physicians analyse what the physician says to the OHS committee in this situation, the physician observed realises that she has not properly explained what the correct space is for a discussion about the employee's unfitness. Because the OHS members perceive the physician to be uncooperative in this situation, they do not support the physician and question her authority, which is a source of considerable stress for the physician.

Let us now look at an extract of some of the discussions between this observed physician and a colleague with similar experience during a cross selfconfrontation meeting about this situation:

Observed physician: They wanted to get me to talk about something when it was the wrong place to do so. Coming back to the young girl herself, I could have talked to them about her, but she would have had to have been present together with management. I meant to say behind closed doors, not in a public meeting. From a physician's point of view, it's not a place where you talk about relocating employees. From a deontological point of view, that was the stance I took.

Colleague: I've also found myself in several situations having to say "you're asking me to do something and I'm saying no." And the employer always takes it really badly. And that makes me wonder about my role as an occupational health physician. If they want to see us backing them up (in the sense of creating a relationship with the employer), are there times when we can say NO right from the start? I'm often like you, they ask me and I say we're not in the right thing. But if they ask me to do something that isn't in line with my missions, perhaps that's because I need to re-explain what my missions are.

When this cross self-confrontation exchange is shown to the physicians' collective, the discussion turns to the position of the occupational health physician within the OHS committee, the drafting of OHS committee reports and the management of emotions. For example:

Observed physician: Can we go even further?... Ask for our remarks to be added to the OHS committee report? I should write down what I said and pass it on.

Colleague 2: Sometimes it's the representatives who take notes and then it's thrown back in our face. I tell them they shouldn't write that, the employees get to read it and it's a bit personal sometimes about illnesses.

Colleague 3: The problem is that whatever's said or written doesn't go down well. D'you think, J., that if you give them a written document, they'll refuse to put it in the report?

Observed physician: I don't know, I could try it in the next OHS committee meeting.

Here, we can see the extent to which the collective exchange contributes to producing room for manoeuvre for this physician who feels helpless. It also fosters the development of skills for all of the other physicians. For example, let us take what the professionals say after the collective discussion work based on the traces of their activity:

Colleague: It helps me to understand better why I acted like that, to realise the way I go about things, which I wasn't necessarily aware of.

Observed physician: It goes even further than the way we do things. At given moments in specific situations, it helps to develop strategies that you don't have.

The prevention of MSD should be situated in a much broader set of activities during which the occupational health physician interacts with the company. This is a subject of discussion between the occupational health physicians as they talk about what stance they should adopt in this working space. Through this discussion the physician is no longer alone deciding how to exercise his or her profession. The exercise is a collective one, spanning different possible stances and furnishing the means for a debate about the role of the occupational health physician in MSD prevention with other prevention specialists and company representatives.

\section{Discussion about innovation and work collectives}

This methodological approach allowed the occupational health physicians involved to set up a collective point of view about the important aspects of their profession that need to be recognised and the variants of this professional genre, notably in relation to the reforms taking place. It also made it possible for the physicians to identify actions leading to more effective MSD prevention. The innovation process triggered by the creation of these physicians' collectives allows the physicians involved in the project to tell their colleagues and other prevention specialists about what is specific to their job as a 
physician compared with other occupational health professionals:

- action occurs during the consultation and has an indirect impact on the organisation of work and the relations between stakeholders

- maintaining the health-work link during consultations has a positive impact on the employee

- consultation and in-company actions are entirely linked in the physician's activity and cannot be separated.

- the occupational health physician's intervention is long term unlike that of other outside professionals

- the working instruments should be transformed into action to contribute to effectiveness and efficiency (unfitness, sharing of computer files, company files, etc.).

In any profession, innovation requires the development of a work collective. However, our research is limited in that the comparison of the two peer groups set up shows that they did not really form work collectives in the strict sense of the term. For the first, where collective work had been developed around the creation of a procedure for employees returning to work, a work collective was indeed formed. For the other, where there had been no prior collective work, the collective emerged with greater difficulty, notably with the departure of one of the members of the group during the actionresearch project.

To conclude, the evaluation of professional practices and multidisciplinarity should be designed with the objective of setting up lasting and effective MSD prevention. This research work invites us to use the creation of a work collective (comprising occupational health physicians in this case) to debate the real professional activity of its members and then work towards setting up cooperation work with different professionals.

\section{References}

[1] Y. Roquelaure, C. Ha, A. Leclerc and al., Epidemiologic surveillance of upper-extremity musculoskeletal disorders in the working population. Arthritis Rheum 55 (2006), 765-78.

[2] S. Stock, Facteurs de risque psychosociaux et TMS, $3^{\text {ème }}$ congrès francophone sur les TMS, Grenoble, 2010.

[3] R. Wells (2009), Why have we not solved the MSD problem. Work.;34:117-21

[4] N. Vézina, The evolution of our representation of WMSD : integrating knowledge and ensuring concerted preventive actions, August $29^{\text {th }}$, Angers, congress PREMUS, 2010, pp. $14-15$

[5] F. Daniellou, MSD prevention : the organisational challenge, August $29^{\text {th }}$, Angers, congress PREMUS, 2010, pp.27_28.
[6] Coutarel, F., Vézina, N., Berthelette, D., et al. (2009) Orientations pour l'évaluation des interventions visant la prévention des Troubles Musculo-Squelettiques liés au travail. Pistes, Perspectives Interdisciplinaires Sur le Travail et la Santé (http://www. Pistes.uqam.ca/), Vol. 11, N² 2, pp. 1-20.

[7] S. Caroly, F. Coutarel, E. Escriva, Y. Roquelaure, J.M. Schweitzer and F. Daniellou (coord.), La prévention durable des TMS: Quels freins ? Quels leviers d'action ? Rapport d'étude pour la Direction Générale du Travail. www.anact.fr, dans dossier thématique TMS, 2008.

[8] G. Baril-Gingras, M. Bellemare et J.P. Brun, Interventions externes en santé et en sécurité du travail : influence du contexte de l'établissement dans l'implantation de mesures préventives ». Relations industrielles / Industrial Relations 61 (1) (2006), 9-41.

[9] S. Caroly, S., C. Cholez, F. Coutarel, B. Dugué, A. Landry, F. Daniellou, Y. Roquelaure and P. Douillet, Prévention durable des TMS: médecine du travail et ergonomie. Premiers résultats d'une recherche nationale pluridisciplinaire. In $\mathrm{J}$. Maline et M. Pottier (dir.), Ergonomie et santé au travail, Transformations du travail et Perspectives pluridisciplinaires Toulouse : Editions Octarès, 2006, pp.449-453.

[10] F. Daniellou and P. Davezies, L'épuisement professionel des médecins généralistes. Une étude compréhensive dans une région. In J. Maline et $\mathrm{M}$. Pottier (dir.), Ergonomie et santé au travail, Transformations du travail et Perspectives pluridisciplinaires Toulouse : Editions Octarès, 2006, pp.4553.

[11] F. Coutarel, Des conditions difficiles d'exercice à la démission d'un médecin du travail en Service autonome: quels enseignements pour l'ergonome et la pluridisciplinarité ? In Congrès de la SELF 2011 (à paraître)

[12] P. Davezies, Réflexion sur la santé au travail. Colloque Travail santé aujourd'hui au tournant du millénaire. 22 novembre, 1997.

[13] F. Consot, P. Frimat and al., Rapport sur le bilan de la réforme de la médecine du travail. Rapport IGAS, ministère des affaires sociales et de la recherche, ocotbre 2007

[14] C. Dellacherie, P. Frimat and G. Leclercq, La santé au travail, visions nouvelles et profession d'avoir. Rapport remis aux ministères du travail, de la santé, de la recherche et du sport. France, Avril 2010

[15] A. Garrigou and G. Peissel-Cottenaz, Pour une rapproche réflexive des besoins en formation des préventeurs. Rapport de Recherche LAP-ADS-IUT HSE, Université Bordeaux 1 et Notes Scientifiques et Techniques $n^{\circ} 244$, INRS, 2004

[16] S. Caroly, F. Coutarel, A. Landry and I Mary-Cheray, Sustainable MSD prevention: management for continuous improvement between prevention and production. Ergonomics intervention in two assembly lines Companies. Applied Ergonomics 41 (4) (2010), 591-599.

[17] P. Rabardel, Les hommes et les technologies. Paris : A. Colin, 1995.

[18] A.Wisner, Réflexions sur l'ergonomie (1962-1995). Toulouse : Octarès Editions, 1995

[19] P. Béguin, Innovation et cadre socio-cognitif des interactions concepteur-opérateur: une approche développementale. Le Travail Humain 70 (4) (2007), 369-390.

[20] F. Daniellou, The French-speaking ergonomists' approach to work activity: cross-influences of field and conceptual models, Theoretical Issues in Ergonomics Sciences 6 (5) (2005), 409-427

[21] P. Falzon, F. Darses, P. Béguin (1996). Collective Design Processes. COOP'96,. Juan les Pins, 12-14 Juin, Pub. INRIA, 1996.

[22] Y. Clot, Travail et pouvoir d'agir. Paris : PUF, 2008. 
[23] S. Caroly, Activité collective et réélaboration des règles : des enjeux pour la santé au travail. Thèse d'habilitation à diriger des recherches. Université de Bordeaux2, France, 2010.

[24] V. Mollo and P. Falzon, Auto- and allo-confrontation as tools

for reflective activities. Applied Ergonomics 35 (2004), 531-54 